\title{
African University Students' Perspectives On Disability Access
}

Shade' Osifuye, University of Minnesota, Twin Cities, USA

Jeanne L. Higbee, Ph.D., University of Minnesota, Twin Cities, USA

\begin{abstract}
Responding to the United Nations Convention on the Rights of Persons With Disabilities (CRPD), this paper reports on the results of one phase of a qualitative research study conducted at a large, public, multi-campus university in East Africa to explore the challenges faced by students with physical disabilities. Recommendations from a focus group are presented and implications for pedagogical and institutional transformation are discussed.
\end{abstract}

Keywords: University Students With Disabilities; United Nations Convention on the Rights of Persons With Disabilities (CRPD); Access To Higher Education

\section{INTRODUCTION: STATEMENT OF THE PROBLEM}

olleges and universities throughout the world have been struggling to make good on the promise of the United Nations (UN; 2006) Convention on the Rights of Persons With Disabilities (CRPD). A common saying among people with disabilities and their allies in the Disability Rights movement is "Nothing about us without us." Student voices can play an important role in assisting postsecondary institutions in breaking down barriers to access and success for students with disabilities. Although this research was conducted at an African university, many of the issues addressed are consistent among university students with disabilities across national boundaries.

\section{DEFINITION OF DISABILITY}

In its Preamble, the UN (2006) CRPD recognizes "the diversity of persons with disabilities" and "that disability is an evolving concept and that disability results from the interaction between persons with impairments and attitudinal and environmental barriers that hinders their full and effective participation in society on an equal basis with others." Article 1 provides the following guideline for who is included in the UN's definition of disability: "Persons with disabilities include those who have long-term physical, mental, intellectual or sensory impairments which in interaction with various barriers may hinder their full and effective participation in society on an equal basis with others."

\section{THEORETICAL FRAMEWORKS}

Principles of universal design (UD; Bowe, 2003; Brugstahler \& Cory, 2008; The Center for Universal Design, 1997) and universal instructional design (UID; Higbee \& Goff, 2008; Silver, Bourke, \& Strehorn, 1998) served as theoretical frameworks to guide this research. Models of disability as described by Evans (2008; Evans \& Herriott, 2009) and others also provided important insights into the particular barriers faced by students with specific disabilities. 


\section{Universal Design}

Article 2 of the UN (2006) CRPD provides the following definition for universal design:

"Universal design" means the design of products, environments, programmes and services to be usable by all people, to the greatest extent possible, without the need for adaptation or specialized design. "Universal design" shall not exclude assistive devices for particular groups of persons with disabilities where this is needed".

The Center for Universal Design, 1997 (UD) has its roots in architecture, encouraging architects to consider all potential users of a building or other space from the very beginning of the design process so that no one will be excluded. Used here, the term universal refers to universal access, not a "one-size-fits-all" approach. For example, drinking fountains might be provided at two or more heights to accommodate people of all heights, including those using wheel chairs. Many architectural features such as ramps, elevators, and automatic door openers are used by everyone, not just by people with disabilities. The guiding principles of UD include (a) "equitable use," (b) "flexibility in use," (c) "simple and intuitive use," (d) "perceptible information," (e) "tolerance for error," (f) "low physical effort," and (g) "size and space for approach and use" (The Center for Universal Design, 1997). Implemented in institutions of higher education, UD considers seating configurations in classrooms; work spaces in laboratories; availability of elevators in multi-story classroom buildings; provision of adaptive technologies such as voice synthesizers and screen readers; captioning of all films and videos; navigation requirements for institution Web sites; transportation and parking issues; signage in multiple formats (e.g., Braille), and so on.

\section{Universal Instructional Design}

Universal instructional design (UID; Higbee \& Goff, 2008; Silver, Bourke, \& Strehorn, 1998) is just one of several models developed to apply UD to educational settings. UID encourages educators to consider the needs of all students when developing curricula, courses, and all course materials, including Web sites and the documents, videos, and other resources posted on them. UID guiding principles (Higbee \& Goff, 2008) are:

- $\quad$ Creating a welcoming learning environment

- $\quad$ Addressing essential course components

- $\quad$ Communicating clear expectations

- $\quad$ Providing constructive feedback

- $\quad$ Providing natural supports (including technology) for learning

- Using teaching methods that consider diverse learning styles, abilities, ways of knowing, and previous experience and background knowledge

- $\quad$ Offering multiple ways for students to demonstrate their knowledge

- $\quad$ Promoting interaction among students and between faculty and students

Each of these guidelines has significant implications for individual faculty, staff, and administrators, as well as for the institution as a whole. For example, in creating a welcoming learning environment, the faculty member may not have control over how rows of chairs are spaced in a lecture hall, but can ensure that all students are treated respectfully. Myers, Lindburg, and Neid (2013) have provided communication tips for interacting with students with disabilities. Faculty, staff, and administrators can play an influential role in educating students about the power of language in creating welcoming learning spaces (Clinton \& Higbee, 2011; Evans \& Herriott, 2009; Tregoning, 2009). The UID guidelines also support the use of more innovative teaching methods rather than relying primarily on lectures and reading course texts, and encourage faculty to move beyond the use of high-stakes objective tests as the sole means of assessing student learning.

Students may be hesitant to disclose a disability (Uncertain Welcome, 2002). Research (Kalivoda \& Higbee, 1995, 1998, 1999) has established that when faculty are required to provide accommodations for students with disabilities, negative attitudes about completing these tasks are often related to the time commitment required and the time frame available, or to the lack of support resources or training in such areas as creating documents that are accessible by screen reader. Thus, although faculty may have positive attitudes toward educational access for postsecondary students with disabilities, they may not be pleased when asked to provide a last-minute 
accommodation like an alternative test format for an individual student with a disability. This problem is exacerbated because faculty at research universities are rewarded in the merit and tenure and promotion systems for their research productivity, not for the difference they can make in the life of a single student by accommodating the student's highly individualized needs related to the challenges of a specific disability. Implementation of UID can reduce the need for students to disclose a disability and for faculty to make individual modifications and accommodations because teaching methods, learning support resources, and methods for the evaluation of student learning are designed from the outset to include all students.

\section{Models of Disability}

Evans and Herriott (2009) discussed historical perspectives on disability. In medieval Europe, people with disabilities were often shunned or hidden from society because they were considered "out of favor with God or possessed by the devil" (p. 30). This perspective is sometimes referred to as the moral model of disability. Beginning in the mid-1800s, proponents of the Eugenics movement viewed people with disabilities as genetically inferior, so they were segregated from mainstream society. Griffin and McClintock (1997) pointed out that a poll conducted in the U.S. in 1937 found that $45 \%$ of the respondents were in favor of euthanizing babies born with birth defects. Evans and Herriott (2009) wrote, "By 1938, forced sterilization of people with genetic illnesses or conditions, as well as those who were deemed feeble-minded, had become the law in thirty-three states" (p. 31).

In some areas in Africa, the cultural beliefs associated with causes of disability may include the following: witchcraft; a curse from gods and ancestors; manifestation of supernatural powers; and punishment for the sins that were committed by tribes, parents or relatives (Mamboleo, 2009). It is not surprising that these beliefs can stigmatize persons with disabilities. Historically these beliefs have resulted in discrimination that limits access and participation for persons with disabilities in education, the work force, and society in general (Mamboleo, 2009).

Beyond the moral model, Evans (2008) described five models of disability that continue to dominate the literature today: (a) medical model, (b) functional limitations model, (c) minority group paradigm, (d) social construction model, and (e) social justice perspective. Each of these models had significance in interpreting the results of this research and will be discussed further in the Discussion and Implications section of this paper.

\section{METHOD}

The qualitative research method used for this research was a focus group. Individual interviews were also conducted, but those results will be reported elsewhere. The population for the study consisted of all undergraduate students with physical disabilities attending any of several campuses of a large, public university in an East African nation. The country in which this research was conducted has signed the UN CRPD.

The five focus group participants included two females and three males who were selected as possible participants through a list obtained from the Coordinator of Students with Disabilities within the Office of the Dean of Students at the university. In December 2012 the five students participated in a 1-hour, in-person focus group discussion, which was recorded and later transcribed for purposes of analysis. The focus group was conducted in English; direct quotes may reflect differences in English usage in different areas of the world. Administrators at the host university provided authorization for this research to be conducted on one of their campuses, and the research proposal for the use of human subjects was also approved by the Institutional Review Board (IRB) at the University of Minnesota, Twin Cities.

\section{Participants}

The names of the students profiled in the following paragraphs are pseudonyms intended to protect the privacy of both the students and the institution they attend. All five participants, regardless of campus, were living in a hostel (i.e., dormitory) and walked to the lecture halls in which their classes were held. 


\section{Mutunga}

At the time that the focus group was conducted, Mutunga was 23 years old and completing his third year at the university, pursing a Bachelors of Education Arts (B.Ed.) in Literature and Linguistics and expected to graduate in 2014. Prior to college Mutunga attended a high school for the blind; he self-identifies as "legally blind" and is the only visually impaired student enrolled on his campus. After he graduates from the university, Mutunga would like to become a human rights activist for Persons with Disabilities.

\section{Mutuku}

At the time of the focus group, Mutuku was a 21-year-old completing his first year at the university, pursuing a Bachelors of Education Arts (B.Ed.) in History and Kiswahili and expected to graduate in 2015. Mutuku identifies himself as Albino; for him remaining shielded from the sun's rays is critical. After Mutuku graduates he would like to pursue a Ph.D. in history in order to become a history professor at a university.

\section{Wangari}

When the focus group met, Wangari was a 21-year-old completing her first year at the university, pursuing a Bachelors of Education (B.Ed.) in History and Kiswahili and expected to graduate in 2015. Wangari identifies her disability as Albinism. After Wangari graduates she would like to teach. Her ultimate goal is to obtain a Ph.D and become a professor.

Njeri

In December 2012 Njeri was a 24-year-old completing her third year at the university, pursuing a Bachelors of Science (B.Sc.) in Meteorology and expected to graduate in 2014. She was living in a hostel and walking to her lecture halls, but the distance was often far from her residence. One of Njeri's legs is shorter than the other, which then requires the use of a prosthetic leg. After Njeri graduates she would like to seek employment in one of the Meteorological offices in her country before pursuing a Master's degree.

Javis

Javis was 22 years old when participating in the focus group. He was completing his second year at the university, pursuing a Bachelors of Education Arts (B.Ed.) in Linguistics and Literature and expected to graduate in 2015. Javis has identified his physical disability as partially blind. Upon graduation Javis would like to pursue a Master's degree in the United States or the United Kingdom.

\section{Instrumentation}

The focus group meeting began with an introduction to the research project and its purpose- to inform administrators at the institution about challenges facing students with physical disabilities and provide recommendations for addressing these challenges-followed by the provision of consent to participate. The students then introduced themselves and talked generally about their courses and teachers at the university before the facilitator began asking more specific questions. The protocol for the focus group included the following prompts:

- What factors, conditions, or structures have enabled you to successfully participate in postsecondary education?

- What factors do you believe limit your potential to successfully navigate through your college courses?

- If there is one thing you would like to see change in a course or in the university as a whole in order to enhance access for students with disabilities, what would it be?

Potential follow-up questions were also included in the protocol, but generally were not used because of the direction of the responses to the original prompts. 


\section{RESULTS}

During the opening discussion in the focus group, students described why they were pursuing a university education. One said:

I really needed a degree. I don't know but I needed one you see, in future I'm planning to be a big umm . . a famous woman, yea, and though this is the only channel since the others they politics... . We've not been given so much, eh, opportunity that you either take or you don't, but it is there as in apart from any other thing in education. We have the opportunity so it's the only thing that we can utilize for us to go through, yea.

This conversation carried over into why students chose this particular university. Several believed that it is important to pave the way for others with disabilities. For example, one student asserted:

I thought that this is the place where I can be helped to achieve my dreams. Secondly, is also to prove to the people who think that the disabled are not able. To prove to them that it's possible for the other disabled to go out and make it there.

This student's response encouraged another to say:

I choose to come here by mind and body. Knowing that very categorically that there are no equipment that could suit my study here, but then I was really strongly driven by two things. One, the urge to make to make sure that uhh ... I had heard that these people here do not know or have not gotten a chance to interact with a person visually challenged and I was strongly filled that I am in a position to undergo the challenges that will be on my way than any other person who has visual challenges.

As I felt if it's not me than there is no any other person, so I was like I have to go to make sure at least the lecturers get used to training persons like me, also the students get used to people like me so when they go and get jobs as employers they meet a person like me they understand they can tell I've lived with a person like this and we associate; he did this and that. So I wanted to create awareness to both the students and the lecturers. Secondly, I felt that you know when you're challenged. Like [another] University is more comfortable as compared to here-is more comfortable in terms of equipment and maybe some other facilities, but then I felt that somewhere where there is no challenge then know I would not develop much, I would need to be challenged. So that I think outside the box, so I felt I had to come here and be challenged and I struggle so that the rest of people who will come after me will not have the same struggle and at last the people that I shall have associated with will be having a good story to tell or an experience to share with some other people out there. That's what drove me to come, actually. I was really persuaded to go to [this university] by my parents, by the University themselves, they wanted me. "Oh, we don't have equipment for you here, now how will you study here?" You know, the [name of university] Chancellor, I remember, I mean the Vice Chancellor, you know, she was talking the same. I was like ahh, okay, I've already decided it was [name of university].

The first prompt focused on successes at the university. One student jumped into the conversation immediately, saying:

Currently the best experience I think I've had is to see positive. When I see the lecturers and the students respond positively to my activity, you know, I just feel so nice when now I am understood by other students, for instance, that I am human. What all they can do, I can do. If it is stealing, I can steal; if it's washing, I can wash-as in I'm just human. They just do not see an angel in me, they see a person with visual challenge, see both abilities and disabilities in me, don't just see the positives and the negatives that are known.

But then I just appreciate because I just feel so good when I succeed to pave the way for other people who come and I was very happy sometime when I just came to realize that it happened that the National Council of Persons with Disabilities awarded me with the best youth award in training and sensitizing people both in [this country] and in even some other few countries. So I was very happy. Now I'm having their word to pay for my master's, you know, I'm happy. 
It was clear from the responses to the prompts that faculty cannot take a one-size-fits-all approach to accommodating students with disabilities, just as a teacher cannot assume that all students have the same preferred learning modalities and ways of knowing. For example, when asked, "What factors, conditions, or structures have enabled you to successfully participate in postsecondary education?" one student responded:

Okay, for me, the one and only thing that enables me to participate it's the fact that they are lecturers ... they recite as in nothing is very practical here as in everything is theory, so and I think that I am very comfortable with theory work.

Meanwhile, when asked, "What factors do you believe limit your potential to successfully navigate through your college courses?" several other students talked about the pitfalls of limiting teaching strategies to lecture alone, including students not feeling engaged, losing focus and attention. Several students addressed problems with seeing the board or screen and not being provided with any notes or copies of lecture materials (e.g., PowerPoint slides) before or after class.

The final prompt asked, "If there is one thing you would like to see change in a course or in the university as a whole in order to enhance access for students with disabilities, what would it be?" Earlier in the focus group, one student had shared a personal challenge: "When I came here my self-esteem was really low, so I was like I had the inferiority complex." This student responded to the final prompt by saying:

I would wish or be very glad if the university would consider having an organization for persons with disabilities and supporting it so that we could be attending the different functions that are always held and also being paid visits by prominent persons who have already made it in life even if it means from other countries. And just motivational tools like I said before, you find that it's difficult to get away from the low self-esteem. It's difficult to raise a person's self-esteem if he's disabled so if things could be happening, then it could be easy to raise the self-esteem of people that are here with disabilities, yes.

Another student, whose response was both highly personal and at the same time concerned for the welfare of others, noted:

As for me, I know I have two disabilities. One is the visual impairment and the other one is the Albinism, which was recognized lately by the National Council of People with Disabilities. It was not there but they recognized it, we argued ourselves, and we were included. First of all, as a person with Albinism, I think the university so far doesn't recognize that ours is a disability, but they should, it is there.

Numerous recommendations focused on modifications that could be made by faculty, such as considering more readable font sizes for materials being projected on a screen, providing more informative and accessible course websites, reserving seats at the front of lecture halls for students with disabilities, and providing notes - whether in advance or following lecture-in both paper and electronic formats. As mentioned previously, some students expressed the need for a shift from relying solely on lecture and textbook reading to convey course content, to teaching methods that engage students and require their participation. However, at least one student recognized that lectures provided the information that would be on the examinations, and that as long as that information was accessible, students could memorize it and be successful.

Other recommendations were focused on changes that need to be made at the institutional level. For example, one student responded:

They should consider the people with physical disabilities when constructing the buildings. I don't think a person using a wheelchair would study here especially in the [name of a specific campus of the institution]. There are stairs everywhere, the hostels [i.e., residence halls], the washrooms, the kitchens. And also, the online registration. For us now, we are registering for rooms online. There should be an option to tick whether you have any challenges because they will just consider like any other person because there's no such options. 
There should also be transport available for people with physical challenges. There are some classes where you have to take some units and classes you have them on main campus, there are classes in the [specific campus]. See, the movement becomes a challenge.

The absence of transportation between the hostels and classroom buildings-whether for students in general, but specifically for students with disabilities, was mentioned often because of implications not only for students with mobility and visual impairments, but also for students with Albinism who cannot endure long periods in direct sunlight. Students also addressed inflexible seating configurations in lecture halls. They commented on long, narrow aisles that are difficult to navigate and chairs that are bolted to the floor. Students complained about inadequate lighting. Another focus of discussion was stairways and the need for elevators in some buildings, or at least - as noted in the previous quote - the option during online registration to indicate the need for classes to meet in rooms that are accessible.

\section{DISCUSSION AND IMPLICATIONS}

Various models of disability are apparent in the student focus group participants' responses. The moral model is reflected in the slow acceptance of Albinism as a disability, despite the UN (2006) CRPD's inclusive definition of what constitutes a disability. In some African cultures, Albinism in a child is still regarded as a curse or punishment visited upon the parents. However, before being too quick in assigning labels like "backward" or "uneducated" to cultures that hold this belief, it is important to consider other disabilities that have been treated similarly worldwide, such as blaming the victims during the emergence of the AIDS epidemic. Across cultures, attitudes toward people with disabilities can still be one of the greatest challenges to access. Thus, disability can be as much a social construction as a lived experience, and meeting the goals of inclusive education for persons with disabilities will require a transformation in how disabilities are perceived - whether physical disabilities like those explored in this research, or cognitive disabilities, emotional disabilities, and so on. One of the views expressed several times in the focus group was that students want others to see them as just like anyone else: "I'm just human." These students have the same kinds of hopes and dreams as students without disabilities, with an added wish to ease the path for the students with disabilities to follow. They are eager to eradicate stereotypes and prove that they are capable of earning a university degree.

The functional limitations model was also present in this focus group discussion; students identified their individual limitations and how they might be addressed. The minority group paradigm was expressed in the students' wish for a student organization that can function as both a support and advocacy group until such time that all cultures value social justice for persons with disabilities in the same way that we would hope they seek social justice for all human beings - regardless of race, religion, gender, sexual identity, and so on. Thus, although the specific recommendations supplied by these students are important, they must be accompanied by a change in attitudes, and these attitudes must be expressed at both the institutional and individual levels.

\section{CONCLUSION}

Full implementation of universal design on college and university campuses is a lofty goal. Many institutions of higher education worldwide were founded long before the emergence of models for inclusion like UD and UID and are challenged to comply with the UN (2006) CRPD and/or local and national legislation. It is expensive to retrofit all buildings with ramps, elevators, and other structural modifications that can be essential to accommodating students with disabilities, and many institutions are already facing other economic challenges. However, there may be little or no expense involved in scheduling classes required by students with disabilities in rooms on the first floor of buildings with accessible entrances. It may not be possible to add electronic door openers and replace door knobs with handles everywhere on campus at one time, but plans can be made to prioritize some buildings and then modify others over time. Similarly, developing an extensive system of transportation for an entire campus may not be financially feasible, but providing a van service for students with disabilities may be a much more affordable solution. Although we would recommend the implementation of universal design wherever possible so that students with disabilities are not placed in the position of having to seek individual accommodations or experience being segregated from others in the educational community, we must be realistic in our goals and 
recognize that change requires time. But we cannot remain complacent and use finances and other challenges as excuses to exclude students with disabilities from the same educational opportunities afforded to all others.

It is also important to note that some desired outcomes can be accomplished by individual faculty members (Duranczyk, Myers, Couillard, Schoen, \& Higbee, 2013). Universally-designed websites that provide academic supports benefit all students, not just those with disabilities. Many students can gain from the use of varying teaching methods to respond to different learning styles. The strategies used to implement UD and UID guidelines in the classroom are often perceived simply as good teaching. But faculty often need training and support to accomplish their UID goals (Durnaczyk et al., 2013), and thus an institutional commitment is still required. The authors wish to thank the members of the administration at the university where this research was conducted for their desire to explore student perceptions so that they can enhance access and success for students with disabilities in the future, thus achieving one of the student focus group participants' goals as well.

Although this focus group was conducted at an African university, it might be anticipated that a similar conversation could occur almost anywhere. Recommendations for future research include mixed methods studies with larger samples across institutional and national boundaries. Any studies undertaken should be followed by reporting back to key figures at the institutions where the research is conducted, as is the goal for this project. It will then be important to conduct ongoing research to keep abreast of progress being made in enhancing inclusion for students with disabilities at individual institutions and worldwide.

\section{AUTHOR INFORMATION}

Shade' Osifuye completed her Master of Arts in Multicultural College Teaching and Learning at the University of Minnesota, Twin Cities in May 2014 and recently accepted a position as a McNair Scholars adviser in the University of Minnesota's TRIO program. Her research interests focus on undergraduate students with disabilities. This paper is an outgrowth of her research at an East African university for her MA capstone project. Her hope is that the results of this research will be used to guide policy, curriculum, and pedagogy to enhance access and success for students with physical disabilities.

Jeanne L. Higbee, Ph.D., has worked in higher education since 1974. Currently she is a Professor in the Department of Postsecondary Teaching and Learning at the University of Minnesota, Twin Cities, where she served as Shade's MA adviser. She is a 2007 American College Personnel Association (ACPA) Diamond Honoree and the recipient of the ACPA Voice of Inclusion Medallion (2005) and Disability Ally Award (2008). In 2011 she received the University of Minnesota's Horace T. Morse-University of Minnesota Alumni Association Award for Outstanding Contributions to Undergraduate Education. In 2013 she received the University's Access Achievement Award. E-mail: higbe002@umn.edu (Corresponding author)

\section{REFERENCES}

1. Bowe, F. G. (2000). Universal design in education-Teaching nontraditional students. Westport, CT: Bergin \& Garvey.

2. Burgstahler, S., \& Cory, R. (Eds). (2008). Universal design of postsecondary education: From principles to practice. Cambridge, MA: Harvard Education Press.

3. Center for Universal Design. (1997). Principles of universal design, Version 2.0. Raleigh, NC: North Carolina State University, Center for Universal Design.

4. Clinton, L., \& Higbee, J. L. (2011). The invisible hand: The power of language in creating welcoming postsecondary learning experiences. Journal of College Teaching and Learning, 8(5), 11-16.

5. Duranczyk, I. M., Myers, K. A., Couillard, E. K., Schoen, S., \& Higbee, J. L. (2013). Enacting the spirit of the United Nations Convention on the Rights of Persons With Disabilities: The role of postsecondary faculty in ensuring access. Journal of Diversity Management, 8(2), 63-72. Retrieved from http://journals.cluteonline.com/index.php/JDM/article/view/8232/8269

6. Evans, N. J. (2008). Theoretical foundations of universal instructional design. I J. L. Higbee \& E, Goff (Eds.), Pedagogy and student services for institutional transformation: Implementing universal design in higher education (pp. 11-23). Minneapolis, MN: University of Minnesota, Center for Research on 
Developmental Education and Urban Literacy. Retrieved from http://www.cehd.umn.edu/passit/docs/PASS-IT-Book.pdf

7. Evans, N. J., \& Herriott, T. K. (2009). Philosophical and theoretical approaches to disability. In J. L. Higbee, \& A. A. Mitchell (Eds.), Making good on the promise: Student affairs professionals with disabilities (pp. 27-40). Washington, DC: American College Personnel Association \& University Press of America.

8. Higbee, J. L., \& Goff, E. (Eds.). (2008). Pedagogy and student services for institutional transformation: Implementing universal design in higher education. Minneapolis, MN: University of Minnesota, Center for Research on Developmental Education and Urban Literacy. Retrieved from http://www.cehd.umn.edu/passit/docs/PASS-IT-Book.pdf

9. Kalivoda, K. S., \& Higbee, J. L. (1995). A theoretical model for the prediction of faculty intention to accommodate disabled students. Journal of the Mid-American Association of Educational Opportunity Program Personnel, 7(1), 7-22.

10. Kalivoda, K. S., \& Higbee, J. L. (1998). Influencing faculty attitudes toward accommodating students with disabilities: A theoretical approach. The Learning Assistance Review, 3(2), 12-25.

11. Kalivoda, K. S., \& Higbee, J. L. (1999). Serving college students with disabilities: Application of the theory of planned behavior. Academic Exchange Quarterly, 3(2), 6-16.

12. Myers, K. A., Lindburg, J. J., \& Neid, D. (2013). Allies for inclusion: Disability and equity in higher education. ASHE Higher Education Report, 39(5). San Francisco, CA: Jossey-Bass.

13. Silver, P., Bourke, A., \& Strehorn, K.C. (1998). Universal instructional design in higher education: An approach for inclusion, Equity \& Excellence in Education, 31(2), 47-51.

14. Uncertain welcome: Student perspectives on disability and postsecondary education [video]. (2002). Minneapolis, MN: University of Minnesota, General College, Curriculum Transformation and Disability. Retrieved from http://mediamill.cla.umn.edu/mediamill/display/70826

15. United Nations. (2006). Convention on the Rights of Persons With Disabilities. New York, NY: Author. Retrieved from http://www.un.org/disabilities/convention/conventionfull.shtml 


\section{NOTES}

